\title{
Continuous formulation for bottom friction in free surface flows modelling
}

\author{
O. Machiels ${ }^{1}$, S. Erpicum ${ }^{1}$, B. J. Dewals ${ }^{1,2}$, P. Archambeau ${ }^{1}$ \\ \& M. Pirotton ${ }^{1}$ \\ ${ }^{1}$ HACH Unit, Department ArGEnCo, University of Liege, Belgium \\ ${ }^{2}$ Belgian Fund for Scientific Research F.R.S-FNRS, Belgium
}

\begin{abstract}
Bottom friction modelling is an important step in river flows computation with $1 \mathrm{D}$ or $2 \mathrm{D}$ solvers. It is usually performed using empirical laws established for uniform flow conditions or a modern approach based on turbulence analysis.

Following the definition of the flow validity field of the main friction laws proposed in the literature, an original continuous formulation has been developed. It is suited to model river flows with a wide range of properties (water depth, discharge, roughness...).

The efficiency of this new formulation, theoretically established and numerically adjusted, is demonstrated through various practical applications. Keywords: shallow water, bottom friction, empirical laws, modern laws.

\section{Introduction}

Shallow Water equations are commonly used to model numerically river flows. Indeed, their main assumption states that the flow velocity component normal to the main flow plane is smaller than the flow velocity components in this plane. This is the case for the majority of river flows where vertical velocity component is negligible regarding the horizontal ones, except in the vicinity of singularities such as weirs for example.

This paper focuses on bottom friction modelling in such mathematical models. This effect is indeed of very high importance for real flow computation despite it is generally evaluated from empirical formulations experimentally determined for uniform flow conditions.
\end{abstract}


The bottom friction term should represent the whole of the energy losses induced by the friction of the fluid on the rough river bed. It is thus related to the bed characteristics (shape, roughness), to the fluid characteristics (viscosity) and to the flow features (water height, velocity).

The concept of friction slope [1] has been early used to characterize bottom friction. It is a non-dimensional number corresponding to the slope of a uniform channel where a uniform flow establishes for a given discharge. This concept is at the basis of the first friction laws proposed in the second part of the $18^{\text {th }}$ century by the researchers of the so called "empirical" school. Authors such as Chézy [2] and Manning [3] proposed laws based on experimental results consisting in measuring the friction slope for a number of idealized flows in a laboratory flume. A second approach appeared later following works of Prandtl [4]. It provided laws issued from analysis of the physics of the shear layer phenomena, referred to as the "modern" school.

Today, both approaches are used by free surface flow modellers, and these laws are sometimes applied to flow conditions far from those on the basis of which they have been developed. It is thus important to keep in mind the validity ranges of each of these laws and to underline the lack of a single formulation able to describe the bottom friction phenomena for largely variable flow conditions.

The aims of the developments presented in this paper were to define and validate an original continuous formulation for bottom friction, contributing to filling this lack.

\section{Main friction laws}

\subsection{Empirical laws}

The laws of the so called "empirical" school have all been developed on the basis of experimental tests. These tests consisted in measuring the slope of a uniform channel where a uniform flow can be obtained [1]. In these flow conditions, the effects of bottom friction are exactly counterbalanced by the gravitational forces. Thus the friction slope is equal to the bottom slope of the channel and simple formulae can be set up to link the channel roughness, the flow variables and the bottom slope. Replacing the bottom slope by the friction slope, the friction effects can be computed for other flow conditions than the uniform ones.

The general form of empirical friction formulations writes:

$$
U=\alpha J^{1 / 2} R_{h}^{\chi}
$$

It relates the friction slope $J$ to hydraulic and geometric parameters affecting the bottom friction such as $U$ the mean flow velocity, $\alpha$ a friction coefficient and $R_{h}$ the hydraulic radius. This last parameter reflects the effect of the cross section shape.

The differences between the different friction formulations of the empirical school are in the $\chi$ exponent value and in the $\alpha$ coefficient form. 
It is important to note that these formulations do not explicitly take into account the turbulence regime of the flow, despite it is well known that this flow state is of great influence on the friction losses.

Chézy [2] and Manning [3] formulations are the most widely used empirical friction laws because of the extensive knowledge of the friction coefficient $\alpha$ available in the literature for both of them. Others exist, such as the laws of Gauckler, Forchheimer, Christen, Hagen and Tillman [1]. They differ only by the exponent of the hydraulic radius in the general formulation (1) as shown in table 1 .

Table 1: Value of $\chi$ exponent of the hydraulic radius for different empirical friction formulations.

\begin{tabular}{|c|c|}
\hline Author & $\chi$ \\
\hline Chézy & 0.5 \\
\hline Manning & 0.667 \\
\hline Gauckler & 0.4 \\
\hline Forchheimer & 0.7 \\
\hline Christen & 0.625 \\
\hline Hagen & 0.714 \\
\hline Tillman & 0.7 \\
\hline
\end{tabular}

\subsection{Modern school}

In contrast with empirical laws, formulations from the modern school rely on a sound theoretical background on the physics of friction phenomena [1].

The developments of the modern school appear one century later than the first empirical developments. Under the leadership of Prandtl, researchers from the University of Göttingen (Germany) developed formulations of a friction coefficient, $\lambda$, function of the turbulence of the flow through the Reynolds number $R e$, and the size of the roughness elements of a pipe, $k$.

Modern formulations have been initially developed for pressurized flows to determine head losses in pipes.

The Darcy-Weisbach relation [5] links the friction slope $J$ to the friction coefficient $\lambda$ :

$$
J=\frac{\lambda}{4 R_{h}} \frac{U^{2}}{2 g}
$$

where $4 R_{h}$ is the equivalent diameter of a channel and $g$ is de gravity acceleration.

In $2 \mathrm{D}$ flow modelling, the hydraulic radius $R_{h}$ is equivalent to the water depth $h$. In the rest of this paper, both expressions will be used similarly.

The friction coefficient $\lambda$ evaluation depends on the flow turbulence regime, and thus the Reynolds. The main modern laws are shown in table 2 and classified depending on the flow turbulence regime. 
Developments on macro-roughness are more recent and are directly related to the development of hydrological modelling. They are associated to the modern school because of the similar form of the mathematical formulations.

Table 2: $\quad$ Main modern laws for friction coefficient depending on the flow turbulence regime.

\begin{tabular}{|c|c|c|c|}
\hline $\begin{array}{l}\text { Flow } \\
\text { turbulence } \\
\text { regime }\end{array}$ & Author & Law & $\begin{array}{l}\text { Theoretical } \\
\text { validity } \\
\text { range }\end{array}$ \\
\hline Laminar & $\begin{array}{l}\text { Poiseuille } \\
\text { [6] }\end{array}$ & $\lambda=\frac{64}{R e}$ & $R e<5000$ \\
\hline $\begin{array}{l}\text { Smooth } \\
\text { turbulent }\end{array}$ & Prandtl [4] & $\sqrt{\frac{1}{\lambda}}=-2 \log \frac{2.51}{\operatorname{Re} \sqrt{\lambda}}$ & $\begin{array}{c}k / h \\
\text { negligible }\end{array}$ \\
\hline Transitional & $\begin{array}{l}\text { Colebrook } \\
\quad[7]\end{array}$ & $\sqrt{\frac{1}{\lambda}}=-2 \log \left(\frac{k}{14.8 h}+\frac{2.51}{\operatorname{Re} \sqrt{\lambda}}\right)$ & $\begin{array}{c}k / h< \\
2240 / R e\end{array}$ \\
\hline $\begin{array}{l}\text { Rough } \\
\text { turbulent }\end{array}$ & $\begin{array}{l}\text { Nikuradse } \\
{[8]}\end{array}$ & $\sqrt{\frac{1}{\lambda}}=-2 \log \frac{k}{14.8 h}$ & $\begin{array}{c}k / h> \\
2240 / R e\end{array}$ \\
\hline $\begin{array}{l}\text { Macro- } \\
\text { roughness }\end{array}$ & $\begin{array}{c}\text { Bathurst } \\
\text { [9] }\end{array}$ & $\sqrt{\frac{1}{\lambda}}=-1.987 \log \frac{k}{5.15 h}$ & $k / h>0.25$ \\
\hline
\end{tabular}

The implicit character of some modern equations gives them an uneasily use. That's the reason why different authors developed explicit equivalent formulations, such as Barr [10] who provides an explicit form of the Colebrook formulation (5), with less than $1 \%$ error on the friction coefficient values:

$$
\sqrt{\frac{1}{\lambda}}=-2 \log \left(\frac{k}{14.8 h}+\frac{4.518 \log \left(\frac{R e}{7}\right)}{\operatorname{Re}\left(1+\frac{\operatorname{Re}^{0.52}\left(\frac{k}{h}\right)^{0.7}}{76.53}\right)}\right)
$$




\section{Validity fields of the mean friction laws}

On one hand, the empirical laws have not been developed regarding the variation in turbulence regime of real water flows. On the other hand, modern laws take better into account the turbulence regime of the flow but none of them can be applied to the whole flow conditions of real river flows. It is thus important to keep in mind the validity fields of the different friction laws, as defined in [11] function of their practical use. These validity fields are shown in terms of relative roughness in the table 3 .

Table 3: $\quad$ Validity fields of the principal friction laws in terms of relative roughness [11].

\begin{tabular}{|c|c|}
\hline Author & Practical validity range $(\mathrm{k} / \mathrm{h})$ \\
\hline Chézy & Near 0 \\
\hline Christen & {$[0 ; 0.032]$} \\
\hline Manning & {$[0.007 ; 0.1]$} \\
\hline Tillman & {$[0.023 ; 0.29]$} \\
\hline Hagen & {$[0.034 ; 0.38]$} \\
\hline Gauckler & No validity \\
\hline Poiseuille & Only laminar \\
\hline Prandtl & Near 0 \\
\hline Colebrook & {$[0 ; 0.1]$} \\
\hline Barr & {$[0 ; 0.1]$} \\
\hline Nikuradse & {$[0 ; 0.1]$} \\
\hline Bathurst & {$[0.1 ; 5.15]$} \\
\hline
\end{tabular}

Today, the empirical laws of Manning and Chézy are the most widely used formulations for friction modelling. This success comes from their simplicity of use and the large existing literature on their parameters values. However, the modern laws are more representative of the physics of bottom friction. Furthermore, explicit forms of the modern laws exist such as the one of Barr (8). The modern laws have thus an important interest for flow modelling.

In practice, other losses, such as those due to the turbulence, are included in the friction term used by most flow solvers. In this case, it is then important to keep in mind that the friction slope $J$ terms in the mathematical model not only represents the bottom friction phenomenon.

\section{Continuous friction formulation}

As shown in table 3, no single formulation is suitable to compute friction effects on the whole range of relative roughness encountered in real river flow, where $h$ goes from 0 on the banks to several meters in the channel centre with an essentially constant roughness height $k$. However, the $k / h$ validity ranges of several laws are contiguous such as for example for Colebrook or Barr and Bathurst. 
Therefore, an original approach has been developed on the basis of the three following statements:

- Barr formula applies for turbulent flows with relative roughness $k / h$ lower than 0.1 .

- Bathurst formula applies to compute friction effect on macro-roughness, i.e. for $k / h$ higher than 0.1 .

- But these two formulations are not equal for a relative roughness $k / h$ in their respective validity fields.

Developments have been performed to link continuously these two formulations close to relative roughness $k / h$ equal to 0.1 [11]. They finally lead to the following expressions which can be used to compute continuously the bottom friction effects in rivers or channels whatever the value of $k / h$ :

For $\frac{k}{h} \leq 0.05:$ Barr formula

For $0.05 \leq \frac{k}{h} \leq 0.15$ :

$\frac{1}{\sqrt{\lambda}}=1469.76\left(\frac{k}{h}\right)^{3}-382.83\left(\frac{k}{h}\right)^{2}+9.89\left(\frac{k}{h}\right)+5.22$

For $\frac{k}{h} \geq 0.15$ : Bathurst formula

\section{Validations}

\subsection{D approach}

Two Belgian river reaches were considered to validate the continuous approach: the Ourthe near the town of Hamoir and the Semois near Membre, fig. 1. These two reaches, respectively $2.6 \mathrm{~km}$ and $1.6 \mathrm{~km}$ long, were selected because of the presence of two gauging stations on both of them. The downstream one combined with the discharge measurement provides the necessary boundary conditions.

Both river reaches have been modelled using the 2D-horizontal finite volumes flow solver WOLF2D, developed at the University of Liege [12], using different friction laws such as Manning, Barr, Bathurst and continuous formulations, with a regular 2 × $2 \mathrm{~m}$ mesh.

The comparison between the upstream water depths computed using the laws of Barr, Manning, Bathurst and the continuous formulation, and the water depth measurements at the upstream gauging station for different discharges has been used to show the interest of the continuous formulation, fig. 2 and 3, and table 4 .

It must be noted that the computation time remains similar whatever the friction law.

The Manning's coefficient $n$ value, which is the inverse of the $\alpha$ coefficient of equation (1), was fitted regarding the real data for the highest discharge. It is 
equal to $0.025 \mathrm{~s} / \mathrm{m}^{1 / 3}$ in the Ourthe and to $0.031 \mathrm{~s} / \mathrm{m}^{1 / 3}$ in the Semois. The constant $k$ value for Barr, Bathurst and continuous formulations was set up to get close to the measurements for both the lowest discharge with Bathurst formulation and the highest one with Barr equation. Its value is $0.09 \mathrm{~m}$ in the Ourthe and $0.3 \mathrm{~m}$ in the Semois.

The water depth is not homogeneous along the river reaches. The $k / h$ ratio indicated in table 4 is thus the ratio value at the upstream limit of the river reaches, at the centre of the cross section. That's the reason why the results provided by the continuous formulation are not exactly equivalent to those provided by the Barr and the Bathurst formulations, respectively for $k / h<0.05$ and $k / h>0.15$.

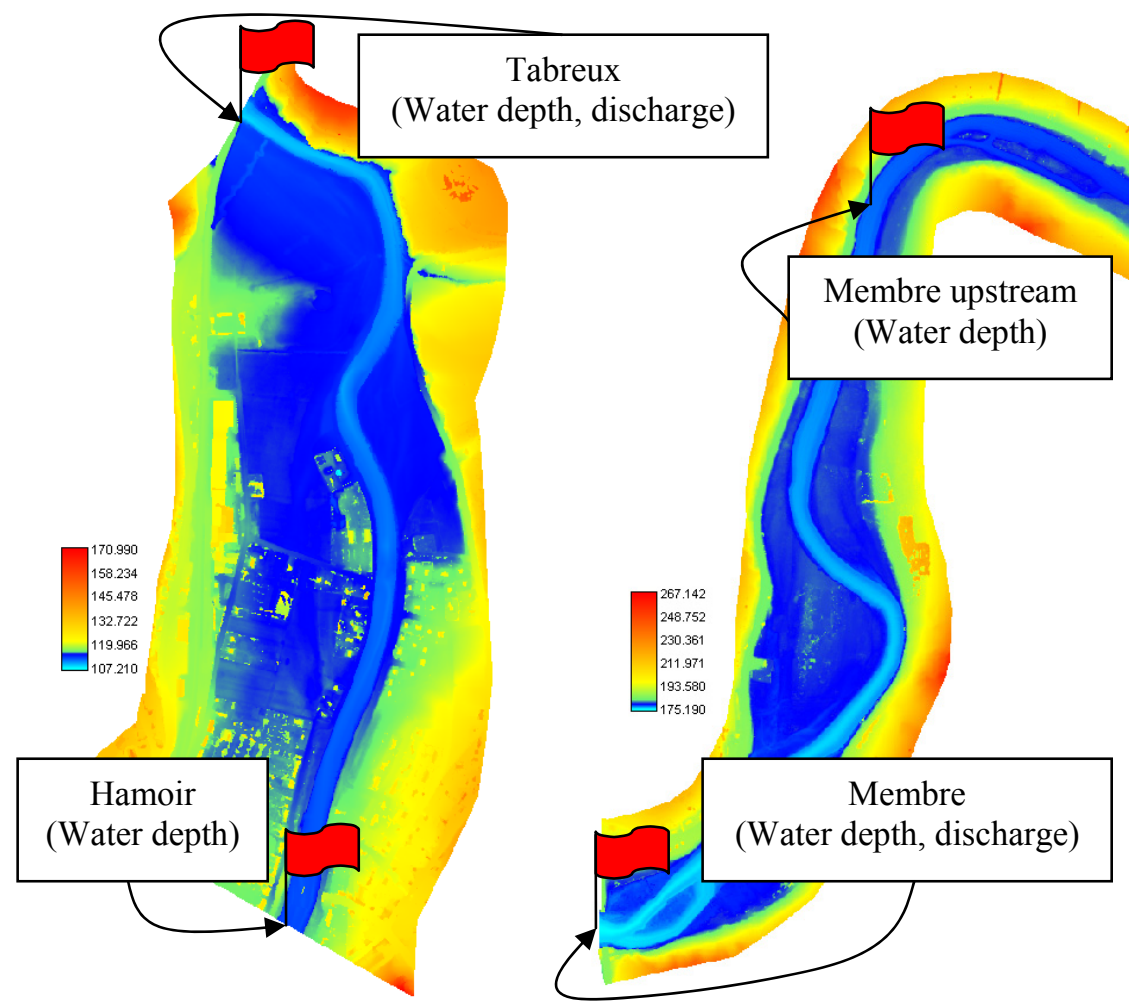

Figure 1: $\quad$ Numerical representation of the topography of the Ourthe River near Hamoir and the Semois River near Membre and location of the gauging stations.

On the Ourthe River, for $k / h$ ratios lower than 0.05 , the water depths computed using Manning, Barr and continuous formulations are relatively close to the measurements (less than 2.5\%), whereas the Bathurst results are less satisfactory (more than $10 \%$ error). This expresses well the validity of Barr and continuous formulations for $2 \mathrm{D}$ free surface flow with low relative roughness 
88 River Basin Management V

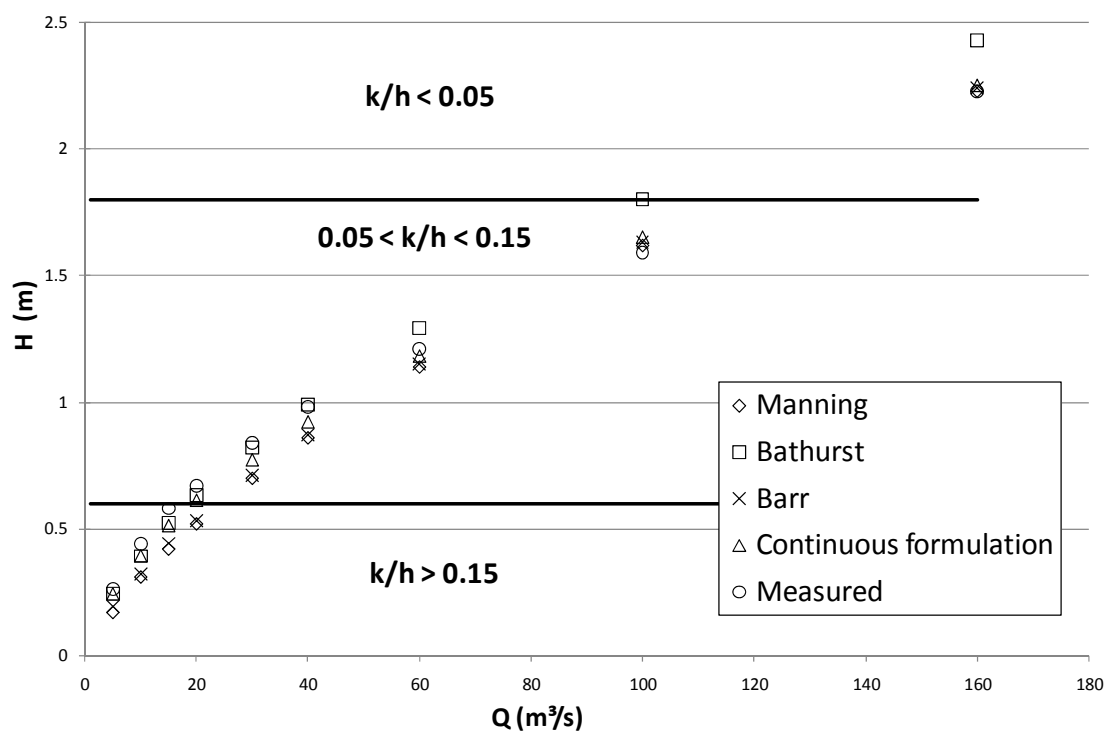

Figure 2: Computed and measured rating curves in Hamoir on the Ourthe River.

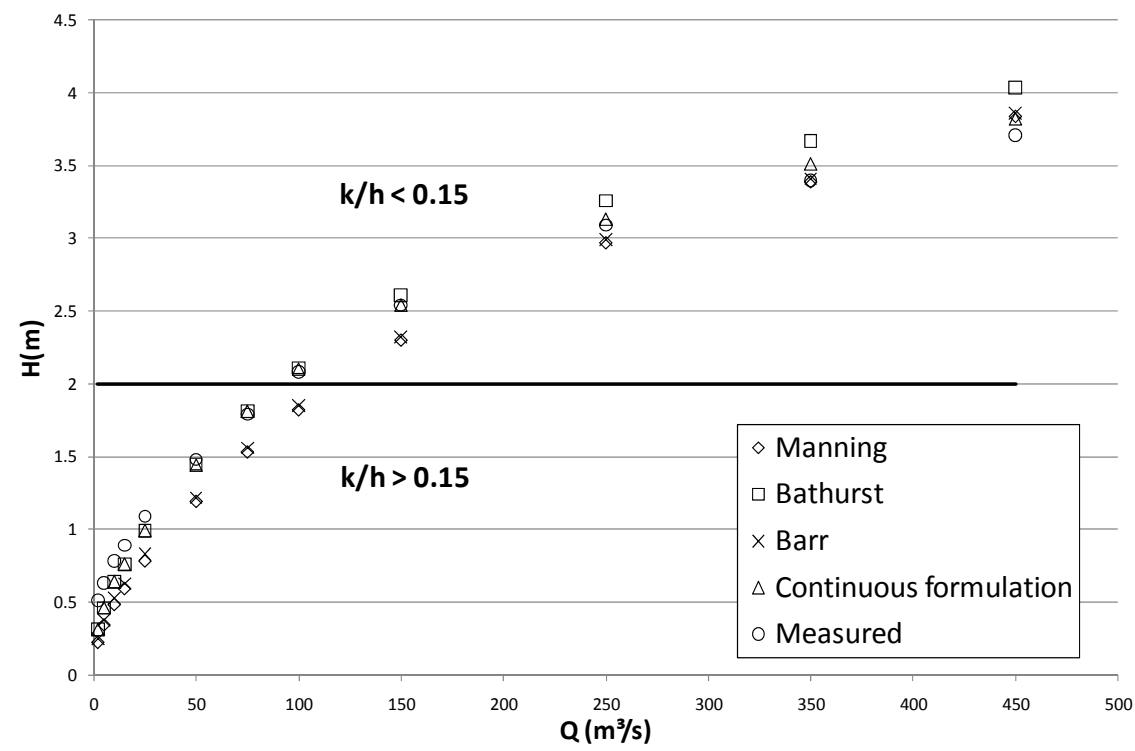

Figure 3: $\quad$ Computed and measured rating curves in Membre on the Semois River.

modelling. This also expresses the efficiency of the Manning's formulation for flow conditions close the validation ones. Finally, this confirms that Bathurst formula does not apply for low relative roughness, as shown in table 3 . 
Table 4: Mean relative error between measured and computed water depths $(\%)$.

\begin{tabular}{|c|c|c|c|c|}
\hline \multirow{3}{*}{ Situation } & Modelling law & $k / h<0.05$ & $\begin{array}{c}0.05<k / h< \\
0.15\end{array}$ & $k / h>0.15$ \\
\hline \multirow{3}{*}{$\begin{array}{c}\text { Hamoir } \\
\text { - Ourthe }\end{array}$} & Manning & 0.9 & 14.3 & 30.6 \\
\cline { 2 - 5 } & Barr & 1.5 & 13.1 & 26.1 \\
\cline { 2 - 5 } & Bathurst & 11.1 & 4.0 & 9.8 \\
\hline \multirow{3}{*}{$\begin{array}{c}\text { Membre } \\
\text { - Semois }\end{array}$} & Manning & 2.3 & 6.4 & 10.3 \\
\cline { 2 - 5 } & Barr & - & 5.9 & 33.9 \\
\cline { 2 - 5 } & Bathurst & - & 5.5 & 29.5 \\
\cline { 2 - 5 } & Continuous formulation & - & 5.3 & 15.9 \\
\hline
\end{tabular}

For $\mathrm{k} / \mathrm{h}$ ratios higher than 0.15 , the water depths, provided using Bathurst and continuous formulations, are the closest to the measurements. The important value of the relative error is partially due to the important effect of measurement uncertainty for low water depths. Indeed, water depth measurements accuracy is close to $5 \mathrm{~cm}$ in these cases. However, the results show the interest of Bathurst and continuous formulations, compared to Manning and Barr ones, for flow modelling on high relative roughness. They also show the limitations of the Barr formulation for high relative roughness and of the Manning's one when flow conditions differ from the validation conditions.

For intermediary $k / h$ ratios, Bathurst formulation remains attractive when the water depths have a low variability on the river reach such as on the Ourthe River. However, when the water depths are more variable, such as on the Semois River, the continuous formulation becomes more accurate.

\section{$5.21 \mathrm{D}$ approach}

Based on water depth and discharge measurements and considering a uniform flow, Martiny [13] determined the $\alpha$ coefficient of Manning equation (1), best known as Strickler coefficient $K$, for a number of Belgian rivers. The uniform flow hypothesis is inaccurate for low water depth. From Martiny's results, three cases, corresponding to the largest rivers studied, have thus been considered: the Warche River in Thioux as well as the Ourthe River in Wyompont and in Amberloup. For these three places, Martiny calculated $K$ values depending on the water depth.

To compare Martiny's results with those provided by the continuous formulation (9), Strickler coefficient was expressed as a function of the friction coefficient $\lambda$. This was obtained by insertion of Manning equation (1) in DarcyWeisbach relation (2): 
90 River Basin Management V

$$
\left.\begin{array}{c}
U=K J^{1 / 2} h^{2 / 3} \\
J=\frac{\lambda}{4 h} \frac{U^{2}}{2 g}
\end{array}\right\} \Rightarrow K=\sqrt{\frac{8 g}{\lambda}} H^{-1 / 6}
$$

Considering the $\lambda$ value provided by continuous formulation (9), equation (10) gives the value of the Strickler coefficient to use for an exact modelling of the continuous friction formulation. Fig. 4, 5 and 6 show the comparison between Martiny's results and those provided by equation (10) considering a particular bottom roughness for each river reach.

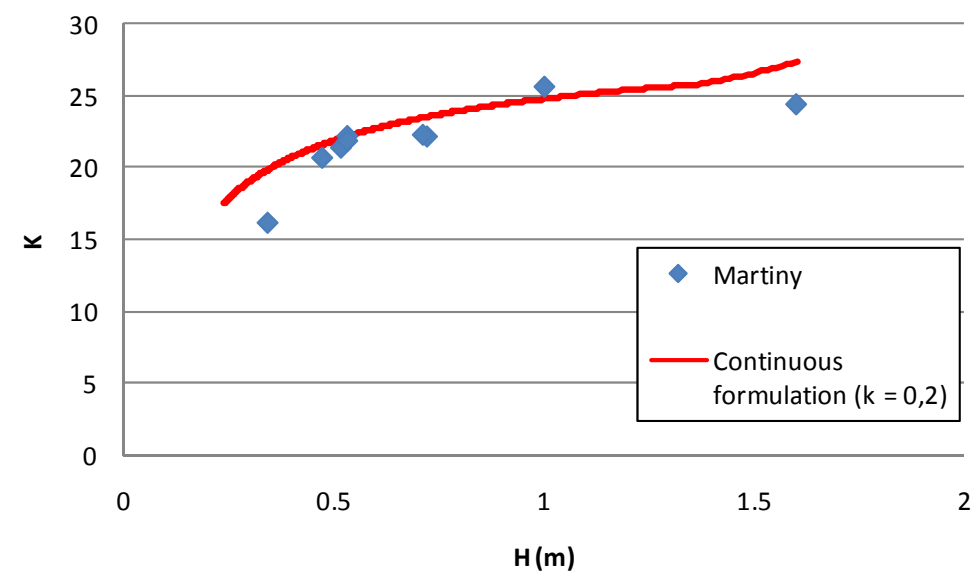

Figure 4: $\quad$ Strickler coefficient value in Thioux on the Warche River.

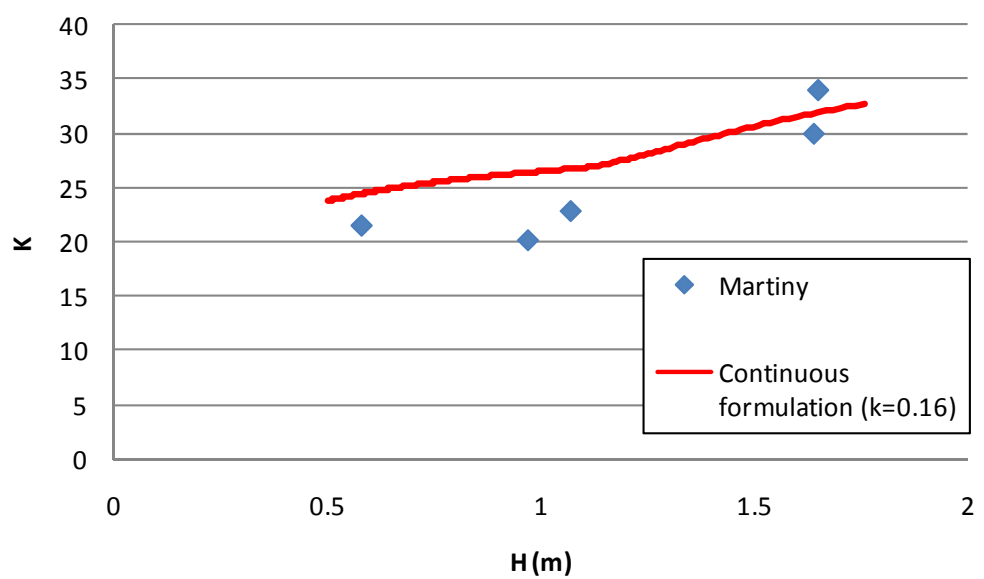

Figure 5: Strickler coefficient value in Wyompont on the Ourthe River. 
In the three cases, the mean relative error on the $K$ value provided by the continuous formulation remains lower than $5 \%$.

This comparison highlights thus the ability of the continuous formulation to describe the friction phenomenon for 1D flow modelling with a single roughness value while the Manning formulation with a single $K$ value is only suited to model the friction for a particular flow.

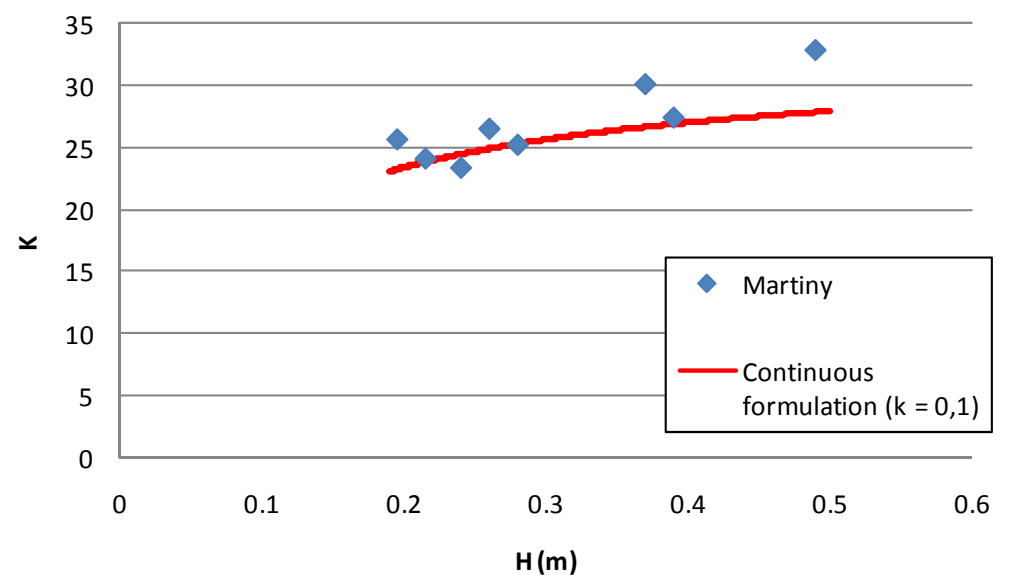

Figure 6: Strickler coefficient value in Amberloup on the Ourthe River.

\section{Conclusions}

Friction is a complex phenomenon with a non negligible influence on river flows characteristics. It is thus necessary to take it into account for a correct flow modelling. Many authors have developed friction formulations. But these laws are not always suited to describe the friction phenomenon in the whole range of real varied flow conditions.

In this study, an original friction law has been developed to fill the lack of a continuous law able to describe the friction phenomenon for the highly variable flow conditions often met in river flows.

This law has been validated for 2D modelling by comparison of water depth values on two different river reaches in Belgium and for 1D modelling by comparison of experimental investigations on three Belgian river reaches.

\section{References}

[1] Carlier, M., Hydraulique générale et appliquée, Eyrolles, Paris, 1972.

[2] Chézy, A., Formule pour trouver la vitesse de l'eau conduite dans une rigole donnée, Dossier 847 (MS 1915) of the manuscript collection of the École National des Ponts et Chaussées, Paris, 1776.

[3] Manning, R., On the Flow of Water in Open Channels and Pipes, Institute of Civil Engineers of Ireland, 1890. 
[4] Prandtl, L., Über Flussigkeitsbewegung bei sehr kleiner Reibung, Verh. III Intl. Math. Kongr., Heidelberg, 1904.

[5] Weisbach, J., Lehrbuch der Ingenieur- und Maschinen-Mechanik, Braunschwieg, 1845.

[6] Poiseuille, J.L.M., Sur le Mouvement des Liquides dans le Tube de Très Petit Diamètre, Comptes Rendues de l'Académie des Sciences de Paris, Vol. 9, 1839.

[7] Colebrook, C.F., Turbulent Flow in Pipes with particular reference to the Transition Region between the Smooth and Rough Pipe Laws, J. Inst. Civ. Engr, No. 4, 1939.

[8] Nikuradse, J., Strömungsgesetze in rauhen Rohren, VDI-Forschungsheft, No. 361, 1933.

[9] Bathurst, J.C., Flow resistance estimation in mountain rivers, J. Hydraul. Eng. - ASCE, 111(4), 1985.

[10] Barr, D.I.H., Solution of the Colebrook-White functions for resistance to uniform turbulent flows, Proc. Inst. Civ. Eng., 1981.

[11] Machiels, O., Erpicum, S., Archambeau, P., Dewals, B.J. \& Pirotton, M., Bottom friction formulations for free surface flow modelling, proc. $8^{\text {th }}$ National Congress on Theoretical and Applied Mechanics, Brussels, 2009.

[12] Erpicum, S., Archambeau, P., Detrembleur, S., Dewals, B.J. \& Pirotton, M., A 2D finite volume multiblock flow solver applied to flood extension forecasting, In: P. Garcia-Navarro, E. Playan (Eds), Numerical modelling of hydrodynamics for water resources, Taylor \& Francis, London, 2007.

[13] Martiny, A., Contribution à la détermination du coefficient de rugosité des rivières, Ministère de la région wallonne, Direction des cours d'eau non navigables, Namur, 1995. 